\title{
Turismo e Parque Eólico: possibilidades para o município de Osório (Rio Grande do Sul, Brasil)
}

\section{Tourism and Wind farm: possibilities for the city of Osório (Rio Grande do Sul, Brazil)}

\author{
Ângela Goldani (GOLDANI, A.) ${ }^{*}$
}

RESUMO - O turismo no litoral norte do estado do Rio Grande do Sul (Brasil) tende a ampliar se houver uma melhor proposta de planejamento, visto que houve um aumento na sua quantidade de potenciais atrativos turísticos, como, por exemplo, a construção do complexo Parque Eólico no município de Osório. O surgimento do parque causou um forte impacto de imagem, além de contribuir para o desenvolvimento do Estado como o maior complexo gerador de energia a partir do vento da América Latina. Este trabalho discute conceitos de turismo, de planejamento turístico, de atrativo turístico e de produto turístico, objetivando principalmente apresentar possibilidades de inserção do Parque Eólico como produto, através do diagnóstico, prognóstico, inventariação e aplicação de técnicas de interpretação patrimonial no local, realizados em junho de 2011, com uma observação simples direta. A pesquisa configurou-se em uma abordagem bibliográfica a respeito do turismo em Osório ligado à existência do parque no município, além de visita técnica com observações locais. A possibilidade de o Parque Eólico ser inserido como produto turístico visa um planejamento responsável e o incremento do turismo no município de Osório, Rio Grande do Sul.

Palavras-chave: Planejamento turístico; Interpretação Patrimonial; Parque Eólico; Osório.

\begin{abstract}
Tourism in the north coast of the state of Rio Grande do Sul (Brazil) tends to increase if there is a better planning proposal, since there was an increase in the quantity of potential tourist attractions, such as the construction of the wind farm complex in the city of Osório. The appearance of the park caused a strong impact image, besides contributed to the development of the state as the biggest wind energy complex generator in Latin America. This paper discusses concepts of tourism, tourism planning, tourism and the attractive tourism product, aiming mainly to show the possibilities of inserting the wind farm as product, through diagnosis, prognosis, inventory and application of techniques of heritage interpretation in the local, conducted in June 2011, with a simple direct observation. The research set up in a bibliographic approach regarding tourism in Osorio linked to the existence of the park in the city, besides technical visit with local observations. The possibility of the wind farm being entered as tourist product aims responsible planning and development of tourism in the city of Osório, Rio Grande do Sul.
\end{abstract}

Key words: Tourism planning; Heritage Interpretation; Wind farm; Osório.

\footnotetext{
Graduação em Turismo (Bacharelado) e em Ciências Biológicas (Licenciatura); Mestrado em Biociências e Doutorado em Zoologia pela Pontifícia Universidade Católica do Rio Grande do Sul (PUCRS). Ocupação Profissional: pesquisadora PDJ (CNPq). Dados para contato: Rua Quintino Bocaiúva 1290/801. Bairro Rio Branco. CEP 90440-050 - Porto Alegre - Rio Grande do Sul (Brasil). Telefones: (51) 33327204 - (51) 99775362. Email: angela.goldani@yahoo.com.br
} 


\section{INTRODUÇÃO}

A Organização Mundial do Turismo (OMT, 2012) define o turismo como um fenômeno social que consiste no deslocamento voluntário e temporário de indivíduos ou de grupos de pessoas que, fundamentalmente, por motivos de recreação, descanso, cultura ou saúde, saem dos seus locais de residência habitual para outro, no qual não exercem nenhuma atividade lucrativa nem remunerada, gerando múltiplas inter-relações de importância social, econômica e cultural.

Para Lockwood e Medlik (2003), o turismo depende do desenvolvimento econômico e de sociedades abertas e livres. E, de acordo com Ruschmann (1997), o planejamento é fundamental e indispensável para o desenvolvimento turístico e equilibrado e em harmonia com os recursos físicos, culturais e sociais das regiões receptoras, evitando, assim, que o turismo destrua as bases que o fazem existir.

Durante décadas, o turismo tem experimentado um crescimento contínuo e uma profunda diversificação para se tornar um dos setores econômicos de maior crescimento no mundo. O turismo está intimamente ligado com o desenvolvimento e há um aumento de oferta de novos destinos a cada ano, transformando-o em um ponto chave do progresso socioeconômico.

Hall (2001) afirma que o planejamento turístico não se refere apenas especificamente à divulgação e ao desenvolvimento do setor, embora estes sejam aspectos importantes. $\mathrm{O}$ turismo deve ser integrado a processos de planejamento mais amplos a fim de promover determinadas metas de melhoria ou maximização econômica, social e ambiental que possam ser atingidas por meio do desenvolvimento turístico adequado. Getz (1987) ressaltou que o planejamento turístico deve ser um processo baseado em pesquisa e avaliação, que busca otimizar o potencial de contribuição do turismo ao bem estar humano e à qualidade do meio ambiente.

Para Barretto (2005, p. 41), existe o seguinte significado de planejamento turístico:

Planejar turismo significa planejar para todos os envolvidos no fenômeno: os que realizam turismo (os turistas) - que são pessoas que muitas vezes sonharam a vida inteira com essa viagem -, os empresários que a comercializam, os que atendem às diversas instalações no local de estada, como os funcionários desses estabelecimentos, sem esquecer os moradores locais que não estão ligados à atividade turística, mas que compartilham o espaço físico e social com os visitantes e o próprio espaço físico, que tem uma capacidade limitada. 
Ainda na mesma linha de raciocínio, Barretto (2005) expõe que planejar turismo significa harmonizar o atendimento às necessidades e propiciar o bem estar de sujeitos sociais provenientes de outro lugar, dentro de uma sociedade receptora e seu meio ambiente, e dos sujeitos dessa sociedade receptora em relação aos turistas e entre si. E isto implica recompensar a comunidade que divide seu espaço com os turistas, financiando, com o dinheiro proveniente do turismo, as obras públicas requeridas para melhorar seu índice de desenvolvimento humano.

Segundo Bignami (2004), o turismo planejado se constitui em uma importante opção para o desenvolvimento sustentável de uma região. As atividades turísticas organizadas em consonância com o respeito ao meio ambiente natural e cultural geram empregos e receitas e, consequentemente melhoram a qualidade de vida de uma comunidade. Os destinos turísticos que se destacam são os que, além de possuírem recursos e atrativos naturais expressivos, oferecem aos visitantes equipamentos e serviços de infraestrutura que proporcionam uma experiência junto à natureza. Por isso, é fundamental que se considere o planejamento e o desenvolvimento de roteiros, de programas e de atividades ligadas ao turismo e uma infraestrutura de apoio adequada.

Osório, por ser um município de menor expressão em relação a outros locais turísticos no Estado do Rio Grande do Sul, passou a ter maior destaque ao receber um grande empreendimento de construção civil no local. Ao ter o tema de energia renovável com natureza preservada segundo informações da Prefeitura (http://www.osorio.rs.gov.br), o município assume um papel essencial na discussão da valorização do turismo e do meio ambiente em locais antes de pouco acesso, com exceção aos moradores locais e alguns visitantes pontuais. Este tema é relevante na medida em que o município de Osório tornou-se mais conhecido a partir de 2006, onde os meios de comunicação (jornais, revistas, sites) divulgaram o início das atividades do parque.

Segundo Yasoshima e Rejowski (2002), em tempos mais recentes no Brasil, a diversificação dos equipamentos e serviços turísticos, a segurança e a rapidez nos transportes, os preços diferenciados permitiram que para muitos o sonho de viajar a lazer se tornasse realidade. Osório, conhecida como a cidade dos bons ventos, já tem como âncora em seu material de divulgação turística o Parque Eólico em primeiro plano, como um grande atrativo. 
Conforme Lage e Milone (2001), produto turístico é o conjunto de bens e serviços relacionados a toda e qualquer atividade de turismo. Como produto turístico, acredita-se que possa haver a possibilidade de atrair mais visitantes, porque propiciará maiores opções de atrações a um roteiro, aquisição de conhecimento a respeito da energia eólica no Brasil e reconhecimento da importância do parque para a região como um bem sustentável. Portanto, para que um conjunto de bens e serviços seja considerado um produto turístico, faz-se necessário a existência de atrativos como insumo para motivar o deslocamento dos turistas, infraestrutura urbana e turística; preço e formas de comercialização. Ou seja, quanto melhor estruturado for o produto turístico, maiores serão os benefícios gerados por ele.

\section{O PARQUE EÓLICO DE OSÓRIO}

Segundo dados do site da empresa Ventos do Sul Energia (http://www.ventosdosulenergia.com.br), o Parque Eólico de Osório em sua denominação oficial, na realidade é um complexo de três parques (Osório, Sangradouro e Índios) geradores de energia a partir do vento, localizado em Osório (Figura 1), município litorâneo do Rio Grande do Sul, Brasil.

FIGURA 1 - MAPA COM PARTE DO LITORAL NORTE DO RS, INCLUINDO A CIDADE DE OSÓRIO.

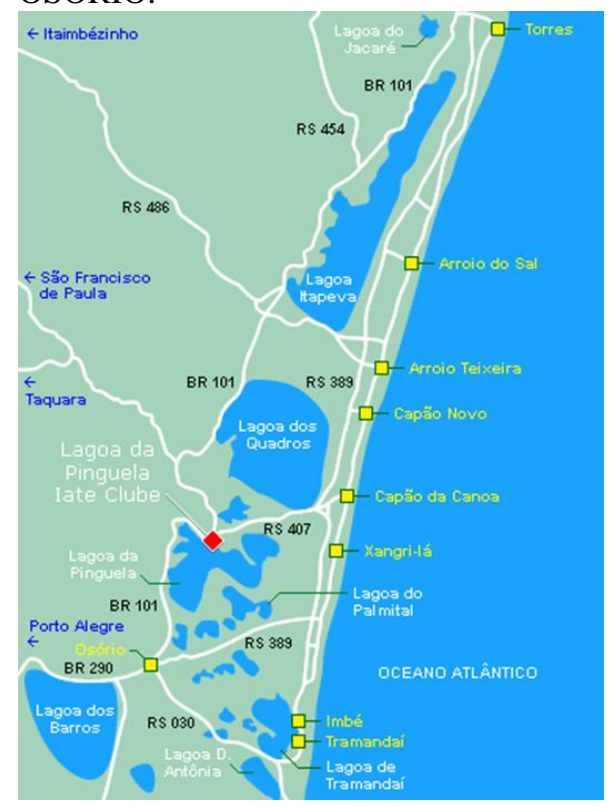

FONTE: GOOGLE IMAGENS. 
O empreendimento tem uma potência instalada de 150 megawatts cada, instalados no alto de torres de concreto de 100 metros de altura (Figura 2). O objetivo deste empreendimento no local é a produção de energia limpa, preservando a fauna e a flora local, e a manutenção das atividades produtivas da região.

FIGURA 2 - AEROGERADORES DO PARQUE EÓLICO DE OSÓRIO.

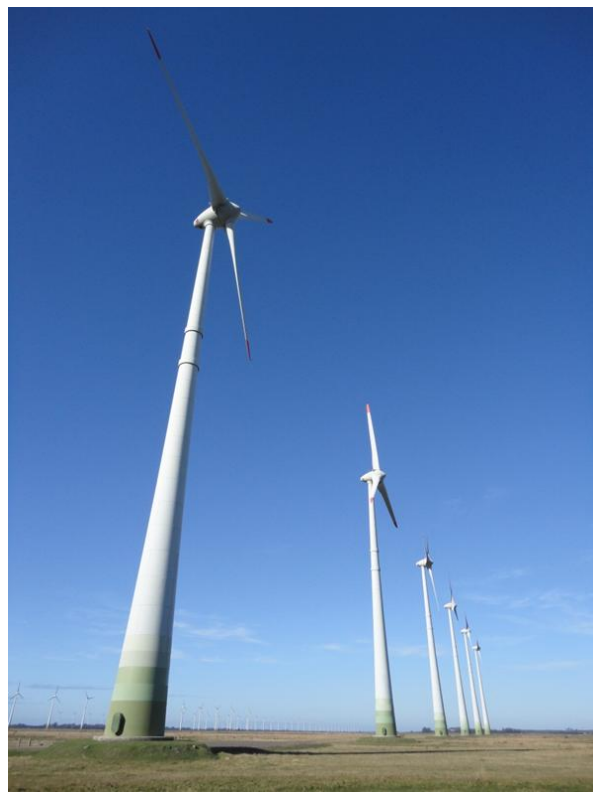

FONTE: A AUTORA.

Ainda segundo a empresa responsável pelo Parque Eólico de Osório (http://www.ventosdosulenergia.com.br), as atividades do complexo iniciaram em 2006, quando o então Presidente da República Luiz Inácio Lula da Silva ligou o primeiro gerador em visita oficial ao parque. A construção se encerrou em dezembro do mesmo ano, e os primeiros 75 aerogeradores passaram a operar comercialmente. Em relação ao meio ambiente, segundo a mesma fonte, o parque evita a emissão de 148.325 toneladas métricas de dióxido de carbono equivalente por ano $\left(\mathrm{tCO}_{2} \mathrm{e} / \mathrm{ano}\right)$ de geração de energia. Como uma medida compensatória, os gestores do parque providenciaram o projeto de construção do mirante do Morro da Borússia e o centro de informações, contribuindo para o incremento do turismo no município.

Os responsáveis pela empresa Ventos do Sul Energia constataram que a implantação dos Parques Eólicos de Osório trouxe importantes benefícios não só para a região de Osório, onde estão instalados, mas também para o País e para o meio ambiente como um todo. $\mathrm{O}$ empreendimento proporcionou transferência de tecnologia 
de ponta e diversificação da matriz energética brasileira, benefícios sociais e econômicos para a região e significativos benefícios ambientais globais e regionais, como observados nas melhorias de acesso em relação às estradas do entorno, a construção do mirante já mencionado acima e o aumento do fluxo de visitantes no município, entre outros.

\section{INVENTARIAÇÃO, PLANEJAMENTO, DiAgNóSTICO E PROGNÓSTICO COMO ASPECTOS METODOLÓGICOS}

O procedimento adotado para a realização e execução desta pesquisa foi fazer primeiramente uma pesquisa bibliográfica (do ponto de vista dos procedimentos técnicos) e uma pesquisa exploratória (do ponto de vista dos objetivos). Uma pesquisa bibliográfica é desenvolvida mediante material já elaborado, principalmente livros e artigos científicos, conforme Gil (1999). A pesquisa exploratória, segundo o mesmo autor, é desenvolvida no sentido de proporcionar uma visão geral acerca de determinado fato. Portanto, esse tipo de pesquisa é realizado, sobretudo, quando o tema escolhido é pouco explorado e torna-se difícil formular hipóteses precisas e operacionalizáveis (RAUPP e BEUREN, 2003).

Uma observação simples direta foi feita no Parque Eólico de Osório, mediante agendamento prévio de visita para o dia 09 de junho de 2011, acompanhando um grupo estudantil (Programa de Pós-Graduação da Pontifícia Universidade Católica do Rio Grande do Sul - Especialização em Gestão da Qualidade do Meio Ambiente), com autorização da empresa responsável pelo parque (Ventos do Sul Energia S. A.) ${ }^{1}$. Conforme Lakatos e Marconi (1996) a observação é uma técnica de coleta de dados para conseguir informações e utiliza os sentidos na obtenção de determinados aspectos da realidade. A técnica de observação é essencial para o pesquisador perceber os elementos importantes e envolventes de um trabalho (local, sujeitos e circunstâncias), as ações a serem tomadas, as anotações de campo e as ideias novas que vão surgindo no decorrer desta observação simples.

\footnotetext{
${ }^{1}$ http://www.ventosdosulenergia.com.br (2011).
} 
Segundo Assis (2004, p. 2), no que diz respeito às visitas técnicas e o espaço produzido como um recurso metodológico aplicado ao turismo:

\begin{abstract}
As características do espaço trabalhado nas visitas técnicas decorrem do conceito que ela exige em transformar o que se observa em realizada e desse modo estabelecer os critério e dissertar (relatório técnico) o que foi vivenciado. Para este caso têm-se umas construções empíricas. Em tempos primórdios já se faziam grandes diagnósticos das áreas estudadas, mas não se tinha uma visão que estava se construindo uma nova identidade do lugar visitado.
\end{abstract}

A técnica de análise dos dados utilizada nesta pesquisa é de caráter qualitativo, indicando os elementos presentes no Parque Eólico de Osório e da sua perspectiva como atrativo turístico e da possibilidade como produto turístico.

Por se tratar de um estudo qualitativo, foram utilizados como indicadores de análise: (1) inventário, (2) planejamento, (3) diagnóstico e (4) prognóstico.

- Inventário: segundo o Ministério do Turismo, o inventário da oferta turística pode ser entendido como o resultado do levantamento, da identificação e do registro dos atrativos, dos serviços e dos equipamentos turísticos e da infraestrutura de apoio ao segmento. No caso do Parque Eólico de Osório foram levantados todos os equipamentos presentes no local, bem como os serviços disponíveis aos visitantes (Quadro 1).

- Planejamento: obtenção de informações relevantes de pesquisa necessárias para identificar o potencial turístico do local. É fundamental para a implementação efetiva das questões levantadas no diagnóstico e prognóstico referentes ao melhoramento do parque e entorno para o turismo em Osório.

- Diagnóstico: levantamento dos elementos turísticos do complexo Parque Eólico de Osório e da análise sobre a existência ou não de infraestrutura para receber turistas (Quadro 2).

- Prognóstico: levantamento das melhorias que poderiam ser sugeridas para o complexo "Parque Eólico de Osório" para identificar potencialidades de inserção do mesmo como produto turístico, levando em consideração a infraestrutura adequada para tal (Quadro 3). 
QUADRO 1 - INVENTÁRIO DO PARQUE EÓLICO DE OSÓRIO

\begin{tabular}{|c|c|c|}
\hline & Categorias de inventariação & Itens de inventariação \\
\hline A. & INFRAESTRUTURA DE APOIO AO TURISTA & $\begin{array}{l}\text { - placas de sinalização } \\
\text { - material de divulgação impresso em } \\
\text { formato de folder } \\
\text { - site da empresa Ventos do Sul } \\
\text { - sala de primeiros socorros }\end{array}$ \\
\hline B. & SERVIÇOS E EQUIPAMENTOS TURÍSTICOS & $\begin{array}{l}\text { - auditório } \\
\text { - Centro Institucional } \\
\text { - Centro de Controle } \\
\text { - } 2 \text { sanitários } \\
\text { - } 25 \text { km de estrada interna } \\
\text { - guarita e portão de entrada }\end{array}$ \\
\hline C. & ATRATIVOS TURÍSTICOS & $\begin{array}{l}\text { - } 75 \text { aerogeradores } \\
\text { * Parque Eólico Sangradouro } \\
\text { * Parque Eólico de Osório } \\
\text { * Parque Eólico dos Índios } \\
\text { - mirante do Centro Institucional } \\
\text { - casa de máquinas } \\
\text { - espelho da água } \\
\text { - fauna e flora } \\
\text { - praça de descanso }\end{array}$ \\
\hline
\end{tabular}

FONTE: A AUTORA.

Após a primeira etapa, o levantamento dos itens de inventariação, seguindo as três categorias expostas no quadro acima, foi feito um diagnóstico do Parque Eólico de Osório.

QUADRO 2 - DIAGNÓSTICO DO PARQUE EÓLICO DE OSÓRIO

\begin{tabular}{|l|l|}
\hline Itens de diagnóstico & Observações \\
\hline 1- promoção e imagem & $\begin{array}{l}\text { A imagem do parque em meios de comunicação corresponde ao esperado, e a } \\
\text { qualidade do material (folder) entregue ao visitante é boa. }\end{array}$ \\
\hline $\begin{array}{l}\text { 2- sequência da } \\
\text { sinalização e acesso } \\
\text { local }\end{array}$ & $\begin{array}{l}\text { A sinalização sequencial é boa na estrada e no paradouro de visualização do } \\
\text { parque, porém ainda deficiente na entrada do complexo, pois não está claro } \\
\text { que naquele local é a entrada oficial do parque. }\end{array}$ \\
\hline $3-$ estacionamento & $\begin{array}{l}\text { O estacionamento no interior do parque é proibido. A única alternativa para } \\
\text { os visitantes que se deslocam em veículos próprios é o estacionamento do } \\
\text { paradouro na estrada. }\end{array}$ \\
\hline 4- portão de entrada & $\begin{array}{l}\text { A qualidade do portão de entrada é ruim. Não estão expostos horários de } \\
\text { funcionamento das visitas, e não há qualquer outra informação para uma } \\
\text { orientação inicial. Há uma guarita muito simples, pequena, escondida, e } \\
\text { apenas um funcionário controlando este acesso. }\end{array}$ \\
\hline $5-$ serviços & $\begin{array}{l}\text { As instalações internas são boas, a limpeza dos ambientes é adequada, e a } \\
\text { qualidade dos sanitários é satisfatória. O problema é que existem somente } \\
\text { dois sanitários para visitantes, um feminino e um masculino. Em um grupo de } \\
\text { cerca de 30 pessoas (o usual) isso se torna um fator de complicação. }\end{array}$ \\
\hline $\begin{array}{l}\text { 6- linguagem das placas } \\
\text { e letreiros }\end{array}$ & Ausência de qualquer placa interpretativa no exterior do parque. \\
\hline $7-$ percurso de visitação & $\begin{array}{l}\text { O percurso é guiado e não há a possibilidade do visitante seguir uma rota no } \\
\text { interior do parque desacompanhado. }\end{array}$ \\
\hline
\end{tabular}

Continua... 
Continuação...

\begin{tabular}{|c|c|}
\hline 8 - temas e histórias & $\begin{array}{l}\text { O tema da visita é bastante técnico, voltado ao público estudantil e com } \\
\text { ênfase em assuntos de meio ambiente energia, conforme o estilo do grupo } \\
\text { durante a visita. Não há qualquer explanação referente ao turismo local } \\
\text { durante a realização da mesma. }\end{array}$ \\
\hline $\begin{array}{l}9 \text { - informação por } \\
\text { etapas }\end{array}$ & $\begin{array}{l}\text { A sequência dos níveis de informação dada pelo condutor é adequada, } \\
\text { partindo sempre do mais simples até chegar às informações mais complexas } \\
\text { no final da visita, de acordo com as áreas abordadas. }\end{array}$ \\
\hline $\begin{array}{l}10-\text { consciência de } \\
\text { mercado }\end{array}$ & $\begin{array}{l}\text { As instalações são adequadas a qualquer perfil de visitante, pois é um } \\
\text { empreendimento inovador na região e de real interesse de todos os visitantes, } \\
\text { tanto pelo apelo do imaginário, quanto pelo apelo da importância da } \\
\text { renovação da energia pelo parque eólico sem poluir o ambiente (público } \\
\text { técnico - engenheiros, biólogos, físicos, químicos,...). }\end{array}$ \\
\hline 11 - atualização & $\begin{array}{l}\text { As informações apresentadas na visita são atuais em termos de conhecimento } \\
\text { e valores. Há uma manutenção diária em todo parque no sistema de } \\
\text { informática (banco de dados). Monitoramento diário da direção e intensidade } \\
\text { dos ventos da região, repassada aos visitantes com informações de interesse e } \\
\text { curiosidades em geral. }\end{array}$ \\
\hline $12-$ manutenção & $\begin{array}{l}\text { Cuidados diários com limpeza e manutenção dos ambientes onde circulam os } \\
\text { visitantes são adequados. }\end{array}$ \\
\hline $\begin{array}{l}13 \text { - experiência } \\
\text { focalizada }\end{array}$ & $\begin{array}{l}\text { A explanação do condutor da visita é adequada ao propósito do grupo } \\
\text { visitante em questão. No caso de } 09 / 06 / 11 \text { o foco dos assuntos e dúvidas foi o } \\
\text { meio ambiente. Foram respondidas todas as questões relativas aos impactos } \\
\text { que o parque causa na natureza, e as medidas compensatórias tomadas. }\end{array}$ \\
\hline $\begin{array}{l}14 \text { - oportunidade de re- } \\
\text { sequenciar }\end{array}$ & $\begin{array}{l}\text { É fácil para o visitante retomar sua própria sequencia, pois a visita segue uma } \\
\text { lógica, porém não é permitido realizá-la individualmente. }\end{array}$ \\
\hline 15 - compras & $\begin{array}{l}\text { Não existem objetos de lembranças (souvenirs) para vender no interior do } \\
\text { parque, nem qualquer tipo de alimento ou bebida. }\end{array}$ \\
\hline 16 - lanchonetes & $\begin{array}{l}\text { Não há serviço de lanchonete para os visitantes. Existe um refeitório } \\
\text { exclusivo aos funcionários do complexo. }\end{array}$ \\
\hline 17 - valores & $\begin{array}{l}\text { A atração reflete uma gama de valores, tais como a importância do } \\
\text { empreendimento para o Rio Grande do Sul, e o aumento da preocupação geral } \\
\text { das pessoas em preservar o meio ambiente e evitar a emissão de gás } \\
\text { carbônico de todas as formas que nos cabem. Em relação ao turismo, a visita } \\
\text { só corrobora o crescimento da região de Osório nesses termos. }\end{array}$ \\
\hline 18 - novas visitas & $\begin{array}{l}\text { O lugar é atraente para um público bem diversificado. A sazonalidade de } \\
\text { turistas na região não interfere muito, pois o atrativo é independente da área } \\
\text { litorânea, podendo ser visitado inclusive no inverno, como foi o caso desta } \\
\text { visita. }\end{array}$ \\
\hline 19 - "boca a boca" & $\begin{array}{l}\text { Há muitos comentários favoráveis aos parques eólicos em geral, no Brasil e } \\
\text { no mundo, expostos em blogs e sites, e inclusive se observa um aumento de } \\
\text { trabalhos acadêmicos sobre o assunto. }\end{array}$ \\
\hline 20 - localização & $\begin{array}{l}\text { A atração é bem divulgada em mapas na Internet, e folhetos em geral da } \\
\text { cidade de Osório, além das placas no entorno (RS } 030 \text { e RST 101). A imagem } \\
\text { dos aerogeradores ("cataventos") virou o símbolo da cidade, tanto em meios } \\
\text { impressos, quanto em meios eletrônicos. }\end{array}$ \\
\hline
\end{tabular}

FONTE: A AUTORA, BASEADA EM 20 ITENS SUGERIDOS EM MURTA E GOODNEY (2002, p. 43) CONVENIENTES PARA A AVALIAÇÃO DE UM ATRATIVO TURÍSTICO.

E após o diagnóstico exposto acima no quadro 2, foram feitas observações através dos itens de prognóstico do Parque Eólico de Osório visando-o como Produto Turístico através das melhorias discutidas neste trabalho. 
QUADRO 3 - PROGNÓSTICO DO PARQUE EÓLICO DE OSÓRIO

\begin{tabular}{|c|c|}
\hline Itens de prognóstico & Observações \\
\hline $\begin{array}{llr}\text { Comunicação } & \text { do } \\
\text { parque com } & \text { o } \\
\text { visitante } & & \end{array}$ & $\begin{array}{l}\text { - implantação de um painel interpretativo no paradouro do parque. } \\
\text { - o uso de narrativas profissionais gravadas em audiofones, que facilitaria uma } \\
\text { interpretação em sequencia adequada e autodidata no interior do parque em } \\
\text { muitos ambientes. } \\
\text { - realocação ou cópia do painel informativo presente no interior do Centro de } \\
\text { Controle para a entrada do parque. }\end{array}$ \\
\hline Marketing Turístico & $\begin{array}{l}\text { - melhoria no folder de apresentação do Parque Eólico, visto que muitas } \\
\text { informações presentes no site oficial do mesmo não foram inseridas neste } \\
\text { material. } \\
\text { - disponibilizar a venda de souvenirs, livros e DVDs do parque (atualmente } \\
\text { entregues somente aos professores dos grupos) para promoção do local. Sugere-se } \\
\text { também disponibilizar a miniatura do aerogerador seguindo modelo do protótipo } \\
\text { já existente. }\end{array}$ \\
\hline Estrutura física & $\begin{array}{l}\text { - disponibilizar mais vagas para cadeirantes, idosos e gestantes no estacionamento } \\
\text { externo (paradouro), onde atualmente só há uma vaga. } \\
\text { - disponibilizar mais sanitários para os visitantes. } \\
\text { - adequar o estacionamento interno dos ônibus de excursão promovendo } \\
\text { melhorias de infraestrutura, tais como sanitários e área de descanso para os } \\
\text { motoristas. } \\
\text { - melhorar a infraestrutura da entrada do parque, implantando um centro de } \\
\text { informações ao visitante e um quiosque para lanches. } \\
\text { - disponibilizar vans para os visitantes percorrerem os } 25 \mathrm{~km} \text { de estrada do } \\
\text { interior do complexo. }\end{array}$ \\
\hline
\end{tabular}

FONTE: A AUTORA, BASEADA NA COMPILAÇÃO DOS ITENS DO QUADRO 2 COMO MELHORIAS PARA TORNAR O PARQUE EÓLICO DE OSÓRIO UM PRODUTO TURÍSTICO.

A análise criteriosa dos itens expostos acima nos quadros 1, 2 e 3 serve de subsídio para a elaboração do complexo em Osório como um produto turístico.

\section{O COMPLEXO COMO PRODUTO TURÍSTICO DE OSÓRIO}

Através do uso da técnica de interpretação patrimonial, Pennyfather (1975) definiu uma série de critérios da comunicação interpretativa que, combinados entre si, podem propiciar ao Parque Eólico de Osório, objeto deste estudo, uma outra perspectiva para visitação, tornando-o mais um produto turístico de Osório.

Murta e Goodney (2002) comentam que independente do tipo de patrimônio utilizado e apresentado aos visitantes como atrativo, o processo de promoção de um produto depende de conceitos claros de interpretação e de comunicação. Trabalhando a partir do diagnóstico e fazendo um prognóstico do Parque Eólico foi possível direcionar melhor a avaliação para indicação de melhorias para potencializá-lo como produto turístico. 
Especificamente, o produto turístico pode ser definido como um produto composto, equivalente a um amálgama formado pelos seguintes componentes: transporte, alimentação, acomodação e entretenimento. Diversos autores como Cabrera (2003), López (2004) e Zárate (2003) reconhecem três dimensões fundamentais do produto turístico: Recursos Turísticos, (naturais e socioculturais expressos no patrimônio do homem), Infraestruturas (transporte e comunicações, facilidades) e Serviços (os que oferecem as empresas de serviços).

O produto turístico é conceituado por Bignami (2004, p. 174) como uma "cadeia de oferta, na qual cada ponto interfere no resultado final e se constitui em um elemento fundamental para a satisfação das necessidades do consumidor" podendo ser compreendido como uma lógica da oferta que apresenta relações diretas entre empresas, indivíduos e entidades (governamentais e não governamentais). Essa oferta apresenta-se identificada como primordial (elementos naturais e culturais) e complementar (infraestrutura turística e local).

Droulers e Milani (2002) afirmam que característico de uma sociedade de consumo, o turismo como um todo estruturado é um produto composto por bens e serviços, tangíveis e intangíveis. Assim, o produto turístico inclui recursos e atrativos naturais e artificiais, equipamentos e infraestruturas, serviços, atitudes recreativas, imagens e valores simbólicos, constituindo-se num conjunto de determinados benefícios capazes de atrair certos grupos de consumidores em busca de uma satisfação das suas motivações e expectativas.

Abaixo se apresenta a listagem desses critérios oriundos da literatura supracitada e as possibilidades de aplicação para o complexo Parque Eólico de Osório:

- estímulo à participação: recepção ao visitante com a implantação do "Memorial do Vento", onde o turista possa interagir com experimentos ligados aos princípios físicos deste fenômeno natural e conhecer melhor a história dos ventos no Rio Grande do Sul e na região de Osório principalmente.

- provocação: a criação de meios de sinalização interpretativa como instrumento de educação ambiental e patrimonial, com placas novas e painéis com riqueza de design e boa localização no interior do parque e no entorno.

- relevância: a criação de um elo entre o passado e o presente na região, como, por exemplo, o acervo da Casa de Osório na Fundação Parque Histórico Marechal 
Manoel Luis Osório, onde estão expostos muitos objetos do patrimônio histórico cultural. No caso do Parque Eólico, uma exposição permanente relacionada à história dos parques eólicos, tais como ferramentas utilizadas na construção, objetos pioneiros, uniformes, documentos, assinaturas de convênios, entre outros.

- ligações com o entorno: disponibilizar um meio de transporte (van) que faria a ligação do parque com o Morro da Borússia, onde o visitante poderia apreciar o parque através do mirante já construído no local e bastante visitado.

- abordagem temática: cada grupo de aerogeradores (Osório, Sangradouro e Índio - três parques dentro do Complexo Parque Eólico) receberia nomes referentes às peculiaridades do Estado, ou seja, um "batismo" das torres de concreto, com placas explicativas sobre a denominação, incentivando ainda mais sobre conhecimentos gerais da região. As sugestões seriam: grupo de aerogeradores "Minuano", “Tuco-tuco" e "Manuel Luís Osório".

- fluxos: a organização espacial da visita ao parque já é uma realidade com as visitas guiadas que ocorrem somente duas vezes na semana, com hora marcada, e apenas em grupos escolares ou pesquisadores, segundo comunicação pessoal com o guia do parque. A proposta é a extensão desta visita com turistas avulsos, e/ou em pequenos grupos, aumentando o fluxo, com a criação de novos horários de visitação, inclusive fins de semana.

- gráficos: confecção de folders criativos para que os turistas tenham um material impresso pertinente e que desperte a vontade de visitar o parque, indicar a outras pessoas e retornar.

- realçando o ambiente: planejamento de trilhas ecológicas para uma interpretação ambiental junto ao parque, acrescentado da venda de produtos artesanais da região e/ou réplicas em miniatura dos aerogeradores realçando o trabalho da comunidade local, enfatizando a atmosfera de sustentabilidade da proposta do Complexo Parque Eólico de Osório.

- o uso do humor: criar caricaturas nas placas informativas do parque, aumentando a captação da atenção do visitante para pequenos detalhes.

- apresentação de períodos de tempo: criar representações gráficas com o uso de cores para demonstração do processo de construção do parque, em todas as etapas com ordem cronológica. 


\section{CONSIDERAÇÕES FINAIS}

O litoral do Brasil é bastante extenso (STROHAECKER; TOLDO JR, 2007), passível de visitação o ano todo, porém na região litorânea do Rio Grande do Sul tem-se a ocorrência da sazonalidade, devido às baixas temperaturas nos meses de inverno. Além disso, observam-se muitas mudanças de comportamento das famílias no decorrer dos anos, e anos atrás o mar bastava para lazer em família, a praia era o refúgio de muitas pessoas nas férias, o local de "veraneio".

Com o desmembramento de Osório para a criação de outros municípios, algumas de suas "praias" ficaram posicionadas em outros municípios, como, por exemplo, Xangri-lá. E, além das lagoas, possui atualmente somente duas praias: Atlântida Sul e Mariápolis, ambas banhadas pelo Oceano Atlântico e pertencentes ao distrito de Atlântida Sul. E o atrativo tem que ter disponível também uma boa estrutura para atrair os visitantes, já que a demanda é limitada muitas vezes aos poucos meses de verão. A esse respeito padronizou-se que um produto turístico é o atrativo somado à infraestrutura adequada para receber turistas.

Além de ser o maior complexo gerador de energia a partir do vento da América Latina, segundo dados extraídos do site da empresa, o Parque Eólico de Osório atrai turistas por conta do diálogo entre o design e a arquitetura de suas dependências e a natureza da região.

Em relação aos outros lugares no mundo que têm Parques Eólicos relacionados também com a questão do turismo local, deve-se destacar o caso da Escócia, onde foi feita uma pesquisa em forma de questionário simples na região de Argyll, e cerca de $80 \%$ dos visitantes afirmaram que estariam interessados em visitar o parque durante a estadia na cidade Alan Mortimer, da empresa ScottishPower do Reino Unido, especializada no assunto, destacou que um inquérito como esse é uma boa notícia para a energia eólica e que envolve as comunidades locais, visando a construção de novas instalações e planos para que os parques eólicos incluam centros de visitantes para satisfazer o interesse do público (http://www.bwea.com/media/news/tourism.html). Esta ideia poderia ser de grande impacto no turismo local de Osório, caso pudesse ser implantada. 
Dentre muitas diretrizes para o desenvolvimento regional no litoral norte do Rio Grande do Sul, propostas inclusive em Strohaecker e Toldo JR (2007), destaca-se a exploração dos parques eólicos como o novo símbolo do Litoral Norte como forma de qualificar a identidade regional, reforçar a singularidade do ambiente natural e incorporar à beleza cênica da região, a energia renovável dos ventos.

Este presente artigo trouxe contribuições de que energias renováveis e o turismo são totalmente compatíveis. Aproveitar o potencial de energias renováveis, enquanto há simultaneamente um aumento na receita de turismo, trará um crescimento econômico sustentável para ambas as partes.

A possibilidade de tornar o Parque Eólico de Osório um produto turístico competitivo na região litorânea do Rio Grande do Sul só tem a contribuir positivamente para o desenvolvimento de Osório e do entorno.

\section{REFERÊNCIAS}

ASSIS, E. A Visita técnica como recurso metodológico aplicado ao turismo. Revista do Turismo, São Paulo, out. 2004.

BARRETTO, M. Planejamento responsável do turismo. Campinas: Papirus, 2005.

BIGNAMI, R. Comunicação como fator estratégico do produto turístico. In: RUSCHMANN, D. V. M; SOLHA, K. T. (Orgs.). Turismo: Uma visão empresarial. Barueri: Manole, 2004.

BWEA News. Disponível em: <http://www.bwea.com/media/news/tourism.html>. Acesso em: 02/05/2011.

CABRERA, J. L. Desarrollo y Promoción de Productos Turísticos. Cuba: Universidad de La Habana, 2003.

DROULERS, M.; MILANI, C. R. S. Desenvolvimento local e turismo em Tarrafal Cabo Verde. Paris: UNESCO, 2002.

GETZ, D. Tourism planning and research: Traditions, models and futures. In: THE AUSTRALIAN TRAVEL RESEARCH WORKSHOP, 1987, Bunbury, Western Australia, p. 5-6.

GIL, A. C. Métodos e técnicas de pesquisa social. São Paulo: Atlas, 1999. 
HALL, M. C. Planejamento turístico: políticas, processos e relacionamentos. São Paulo: Contexto, 2001.

LAGE, B. H. G.; MILONE, P. C. Economia do Turismo. São Paulo: Atlas, 2001.

LAKATOS, E. M.; MARCONI, M. de A. Técnicas de Pesquisa. São Paulo: Atlas, 1996.

LOCKWOOD, A.; MEDLIK, S. Turismo e Hospitalidade no Século XXI. São Paulo: Manole, 2003.

LÓPEZ, J. J. S. "Benidorm, presente y futuro de um producto turístico"en línea. In: Contribuciones a la Economía, 2004. Disponível em: 〈http://www.eumed.net/ce〉. Acesso em: 05/04/2011.

MURTA, S. M.; GOODNEY, B. Interpretação do patrimônio para visitantes: um quadro conceitual. In: MURTA, S. M.; ALBANO, C. (Orgs.). Interpretar o patrimônio: um exercício do olhar. Belo Horizonte: Ed. UFMG; Território Brasilis, 2002.

ORGANIZAÇÃO MUNDIAL DO TURISMO (OMT). Disponível em: <http://www.world-tourism.org>. Acesso em: 09/10/2012.

PENNYFATHER, K. Guide to Countryside Interpretation, Part II: Interpretive Media and Facilities. HMSO for Countryside Commission for Scotland, 1975.

RAUPP, F. M.; BEUREN, I. M. Metodologia da pesquisa aplicável às ciências sociais. In: LONGARAY, A. A.; BEUREN, I. M. (Orgs.). Como elaborar trabalhos monográficos em contabilidade: teoria e prática. São Paulo: Atlas, 2003.

RUSCHMANN, D. V. de M. Turismo e planejamento sustentável: A proteção do meio ambiente. Campinas, SP: Papirus, 1997.

STROHAECKER, T. M.; TOLDO JR., E. E. O litoral norte do Rio Grande do Sul como um pólo de sustentabilidade ambiental do Brasil Meridional. Scripta Nova. Revista Electrónica de Geografía y Ciencias Sociales. Barcelona, Universidad de Barcelona, v.11, n. 245 (39), 2007.

VENTOS DO SUL. Disponível em: <http://www.ventosdosulenergia.com.br>. Acesso em: $15 / 04 / 2011$.

YASOSHIMA, J. R.; REJOWSKI, M. (Orgs.). Turismo no percurso do tempo. São Paulo: Aleph, 2002. 
ZÁRATE, O. H. R. La influencia del flujo turístico em la demanda de trabajo del mercado laboral estructurado em la ciudad de Huancayo. Peru: Nueva Historia, 2003.

Recebido em: 12-11-2012

Aprovado em: 12-12-2012 